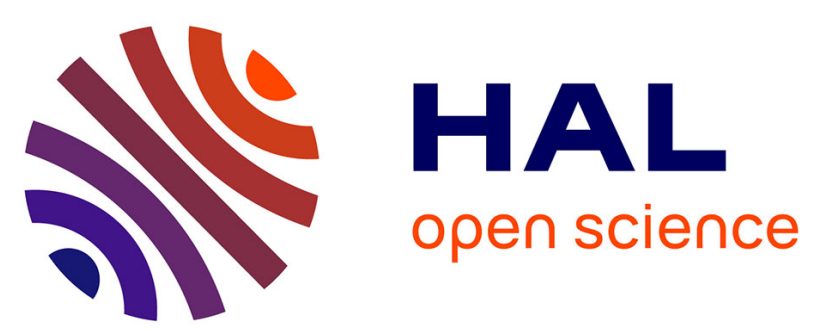

\title{
There is room for selection in a small local pig breed when using optimum contribution selection: A simulation study
}

Jean-Luc Gourdine, Anders Christian Sorensen, Lotta Rydhmer

\section{- To cite this version:}

Jean-Luc Gourdine, Anders Christian Sorensen, Lotta Rydhmer. There is room for selection in a small local pig breed when using optimum contribution selection: A simulation study. Journal of Animal Science, 2012, 90 (1), pp.76-84. 10.2527/jas.2011-3898 . hal-02644741

\section{HAL Id: hal-02644741 \\ https://hal.inrae.fr/hal-02644741}

Submitted on 28 May 2020

HAL is a multi-disciplinary open access archive for the deposit and dissemination of scientific research documents, whether they are published or not. The documents may come from teaching and research institutions in France or abroad, or from public or private research centers.
L'archive ouverte pluridisciplinaire HAL, est destinée au dépôt et à la diffusion de documents scientifiques de niveau recherche, publiés ou non, émanant des établissements d'enseignement et de recherche français ou étrangers, des laboratoires publics ou privés. 


\section{JOURNAL OF ANIMAL SCIENCE \\ The Premier Journal and Leading Source of New Knowledge and Perspective in Animal Science}

\section{There is room for selection in a small local pig breed when using optimum contribution selection: A simulation study}

J. L. Gourdine, A. C. Sørensen and L. Rydhmer

J ANIM SCI 2012, 90:76-84.

doi: 10.2527/jas.2011-3898 originally published online August 12, 2011

The online version of this article, along with updated information and services, is located on the World Wide Web at:

http://www.journalofanimalscience.org/content/90/1/76 


\title{
There is room for selection in a small local pig breed when using optimum contribution selection: A simulation study ${ }^{1,2}$
}

\author{
J. L. Gourdine, ${ }^{*} \ddagger^{3}$ A. C. Sørensen, $\dagger$ and L. Rydhmer $\ddagger$ \\ *INRA UR143, French National Institute for Agricultural Research, Tropical Animal Science Unit, \\ 97170 Petit Bourg, Guadeloupe, F.W.I., France; †Aarhus University, Department of Molecular Biology \\ and Genetics, PO Box 50, DK-8830 Tjele, Denmark; and $\ddagger$ Swedish University of Agricultural Sciences, \\ Department of Animal Breeding and Genetics, Box 7023, SE-75007 Uppsala, Sweden
}

\begin{abstract}
Selection progress must be carefully balanced against the conservation of genetic variation in small populations of local breeds. Well-defined breeding programs with specified selection traits are rare in local pig breeds. Given the small population size, the focus is often on the management of genetic diversity. However, in local breeds, optimum contribution selection can be applied to control the rate of inbreeding and to avoid reduced performance in traits with high market value. The aim of this study was to assess the extent to which a breeding program aiming for improved product quality in a small local breed would be feasible. We used stochastic simulations to compare 25 scenarios. The scenarios differed in size of population, selection intensity of boars, type of selection (random selection, truncation selection based on
\end{abstract}

BLUP breeding values, or optimum contribution selection based on BLUP breeding values), and heritability of the selection trait. It was assumed that the local breed is used in an extensive system for a high-meatquality market. The simulations showed that in the smallest population (300 female reproducers), inbreeding increased by $0.8 \%$ when selection was performed at random. With optimum contribution selection, genetic progress can be achieved that is almost as great as that with truncation selection based on BLUP breeding values ( 0.2 to 0.5 vs. 0.3 to 0.5 genetic SD, $P<0.05$ ), but at a considerably decreased rate of inbreeding ( 0.7 to 1.2 vs. 2.3 to $5.7 \%, P<0.01)$. This confirmation of the potential utilization of OCS even in small populations is important in the context of sustainable management and the use of animal genetic resources.

Key words: breeding goal, inbreeding, local breed, optimal contribution selection

(C) 2012 American Society of Animal Science. All rights reserved.

J. Anim. Sci. 2012. 90:76-84 doi:10.2527/jas.2011-3898

\section{INTRODUCTION}

Local breeds are defined as those that occur in only 1 country (FAO, 2007). European local pig breeds of-

\footnotetext{
${ }^{1}$ The authors gratefully acknowledge European Community financial participation under the Sixth Framework Programme for Research, Technological Development and Demonstration Activities, for the Integrated Project Q-PORKCHAINS FOOD-CT-2007-036245. The authors also thank Karel de Greef, at the Animal Sciences Group of Wageningen University (Wageningen, the Netherlands), for inspiring discussions and valuable comments.

${ }^{2}$ Disclaimer: The views expressed in this publication are the sole responsibility of the authors and do not necessarily reflect the views of the European Commission. Neither the European Commission nor any person acting on behalf of the Commission is responsible for the use that might be made of the information. The information in this document is provided as is and no guarantee or warranty is given that the information is fit for any particular purpose. The user thereof uses the information at his or her sole risk and liability.

${ }^{3}$ Corresponding author: Jean-Luc.Gourdine@antilles.inra.fr

Received January 21, 2011.

Accepted August 4, 2011.
}

ten differ from the major breeds and commercial lines, which are mostly related to Duroc, Hampshire, Landrace, Large White, and Pietrain pigs. Ollivier et al. (2005) used a sample of 68 European pig breeds, including 29 local breeds, to study genetic diversity. The local breeds accounted for $56 \%$ of the total betweenbreed microsatellite diversity. The local pig breeds represent $48 \%$ of the total number of pig breeds (FAO, 2007), and biodiversity can be maintained by keeping and using a sufficient number of breeds. This will secure the availability of important genes for future needs (Fimland, 2007). Furthermore, "loss of local breeds will cause cultural erosion and diminish the ability of communities to maintain their cultures and livelihoods," as stated in the Global Plan of Action for animal genetic resources and the Interlaken Declaration (FAO, 2007, p. 29). Thus, the maintenance of local breeds in pork production seems to be strategically important. Except for the large Iberian pig population, selection for genetic improvement of local pig breeds in well-defined breeding programs is rare. 
For the majority of local breeds, such as the Basque (Mercat, 2007) and the Majorcan (Jaume et al., 2008), the focus is on management of genetic diversity. This agrees with the Convention on Biological Diversity, which states that the components of biological diversity should be used in a way and at a rate that does not lead to a long-term decline of that diversity, thereby maintaining its potential to meet the needs and aspirations of present and future generations (CBD, 2004). However, with pedigree information, optimum contribution selection (OCS; Meuwissen, 1997; Grundy et al., 2000) can be applied to control inbreeding rates and simultaneously avoid reduced performance in valuable traits. According to Gandini and Oldenbroek (2007), strategies for moving from conservation to utilization include defining the relevant breeding goal and marketing products to secure profitability. If the products are being marketed as "high quality," it may be advisable to select for improved meat quality of the breed.

The main objective of the present paper was to show, using stochastic simulation, that it is possible to design a breeding program to improve a key trait in a small local breed population without increasing the rate of inbreeding above the recommended rate. A meat quality trait (MQT) was chosen as the trait under selection, but the results apply to any trait of importance in the marketing of high-quality products from a local breed.

\section{MATERIALS AND METHODS}

Animal Care and Use Committee approval was not obtained for this study because no animals were used.

\section{Scenarios}

A number of scenarios were designed to emulate different breeding strategies in populations of local breeds of pigs. A total of 25 scenarios were modeled for 3 population sizes, 2 selection intensities of boars, 2 heritabilities of the trait under selection, and 3 selection strategies (Table 1).

\section{Selection Strategies}

Random selection (RS) within sex was used as a benchmark of the least possible rate of inbreeding. These scenarios were performed for only 1 heritability $\left(\mathbf{h}^{2}\right)$ because this parameter had no impact in this case. The second selection strategy was truncation selection (TS) based on BLUP breeding values. The third selection strategy was OCS based on BLUP breeding values. In principle, OCS is obtained by maximizing the term C, defined as follows (Wray and Goddard, 1994):

$$
\mathrm{C}=\mathbf{x}^{\prime} \hat{\mathbf{a}}+\lambda \mathbf{x}^{\prime} \mathbf{A} \mathbf{x}
$$

Here $\mathbf{x}$ is a vector of contributions in which the contribution $x_{i}$ of animal $i$ to the next generation is $x_{i}=$
$1 / 2\left(n_{i} / N\right)$, with $n_{i}$ being the number of offspring from animal $i$ and $N$ being the total number of offspring; $\hat{a}$ is a vector of EBV, and $\lambda$ is the weight relative to breeding values given to the average relationship between candidates and all potential breeding animals in the population weighted according to their proposed contribution $\left(\mathbf{x}^{\prime} \mathbf{A} \mathbf{x}\right)$. $\mathbf{A}$ is the relationship matrix among those animals. The term $\lambda$ (which has a negative value) can be interpreted as the cost of inbreeding, paid in reduced genetic gain and genetic gain not expressed because of inbreeding depression. The maximization of $\mathrm{C}$ in this study was performed by the software EVA (Evolutionary Algorithms) developed by Berg et al. (2009). The EVA software uses an evolutionary algorithm to find the solution vector containing $n_{i}$, for all selection candidates, that maximizes $\mathrm{C}$, when $n_{i}$ is expressed as $x_{i}$.

As pointed out by Sørensen et al. (2008), it is difficult to specify the weight $\lambda$ because this depends on various factors, such as inbreeding depression, time horizon, and genetic gain. In this study, preliminary simulations were undertaken to specify $\lambda$ before running the final OCS scenarios. Values of $\lambda$ from -1 to -150 were used in the scenario with the smallest population size (scenario OCS30NS.4) over 5 yr (Figure 1). With $\lambda$ equal to -50 , the rate of inbreeding did not exceed $1 \%$ per generation. This value of $\lambda$ was used thereafter in all OCS simulations.

\section{Population Structure}

A pig population with the characteristics of a small local breed was simulated. It was assumed that the local breed was reared in an extensive system, with a constant number of 10 or 24 sows in each herd. The population sizes and structures varied between 300 female reproducers in 30 herds, 840 female reproducers in 35 herds, and 1,848 female reproducers in 77 herds. The production system was small-scale commercial production of high-quality products for a niche market. The breeding goal consisted of $1 \mathrm{MQT}$, recorded at the slaughterhouse. The products were marketed as "high-quality meat from a local breed." To obtain meat of high quality, slaughter weight was heavy and age at slaughter was greater than the age of first service. Each sow weaned 3 female and 3 male piglets and produced 2 litters per year, to a maximum of 6 litters. This corresponded to a rate of annual sow replacement of $17 \%$. Of the male piglets, at random 2 were castrated and 1 was kept intact in each litter. Castration was performed within the first week after birth.

In an extensive production system, where animals are kept outdoors on pasture or in the forest, it is important to keep sow families together. Thus, the replacement of sows involved the selection of the best gilts as substitutes within the herd, and there was no exchange of gilts between herds. Figure 2 summarizes the simulated structure within a herd. Two types of mating, 
Table 1. Summary of input parameters for the 25 simulated scenarios

\begin{tabular}{|c|c|c|c|c|}
\hline $\begin{array}{l}\text { Number } \\
\text { of herds }\end{array}$ & Type of mating & $\mathrm{h}^{2}$ of trait & $\begin{array}{l}\text { Selection } \\
\text { strategy }^{1}\end{array}$ & $\begin{array}{l}\text { Scenario } \\
\text { abbreviation }\end{array}$ \\
\hline \multirow[t]{5}{*}{30} & \multirow[t]{5}{*}{ Natural service } & - & $\mathrm{RS}$ & RS30NS \\
\hline & & 0.22 & TS & TS30NS.2 \\
\hline & & 0.22 & OCS & OCS30NS.2 \\
\hline & & 0.44 & TS & TS30NS.4 \\
\hline & & 0.44 & OCS & OCS30NS.4 \\
\hline \multirow[t]{10}{*}{35} & \multirow[t]{5}{*}{ Natural service } & - & RS & RS35NS \\
\hline & & 0.22 & TS & TS35NS.2 \\
\hline & & 0.22 & OCS & OCS35NS.2 \\
\hline & & 0.44 & TS & TS35NS.4 \\
\hline & & 0.44 & OCS & OCS35NS.4 \\
\hline & \multirow[t]{5}{*}{$\mathrm{AI}$} & - & RS & RS35AI \\
\hline & & 0.22 & TS & TS35AI.2 \\
\hline & & 0.22 & OCS & OCS35AI.2 \\
\hline & & 0.44 & TS & TS35AI.4 \\
\hline & & 0.44 & OCS & OCS35AI.4 \\
\hline \multirow[t]{10}{*}{77} & \multirow[t]{5}{*}{ Natural service } & - & RS & RS77NS \\
\hline & & 0.22 & TS & TS77NS.2 \\
\hline & & 0.22 & OCS & OCS77NS.2 \\
\hline & & 0.44 & TS & TS77NS.4 \\
\hline & & 0.44 & OCS & OCS77NS.4 \\
\hline & \multirow[t]{5}{*}{$\mathrm{AI}$} & - & RS & RS77AI \\
\hline & & 0.22 & TS & TS77AI.2 \\
\hline & & 0.22 & OCS & OCS77AI.2 \\
\hline & & 0.44 & TS & TS77AI.4 \\
\hline & & 0.44 & OCS & OCS77AI.4 \\
\hline
\end{tabular}

${ }^{1} \mathrm{RS}=$ random selection; TS = truncation selection based on BLUP breeding values; OCS = optimum contribution selection.

resulting in 2 different selection intensities of boars, were simulated: natural service (NS) and AI. In the first, only NS was performed. There was 1 boar per herd in scenarios with 30 herds and 2 boars per herd in other scenarios, which corresponded to a mating ratio of 10 or 12, respectively. Selection of NS boars was performed across herds, but selected boars were exchanged between herds only if there were not exactly 2 boars selected within that particular herd. Herds with fewer than 2 boars selected received a boar at random from a herd with more than 2 boars selected. With AI, the ex-

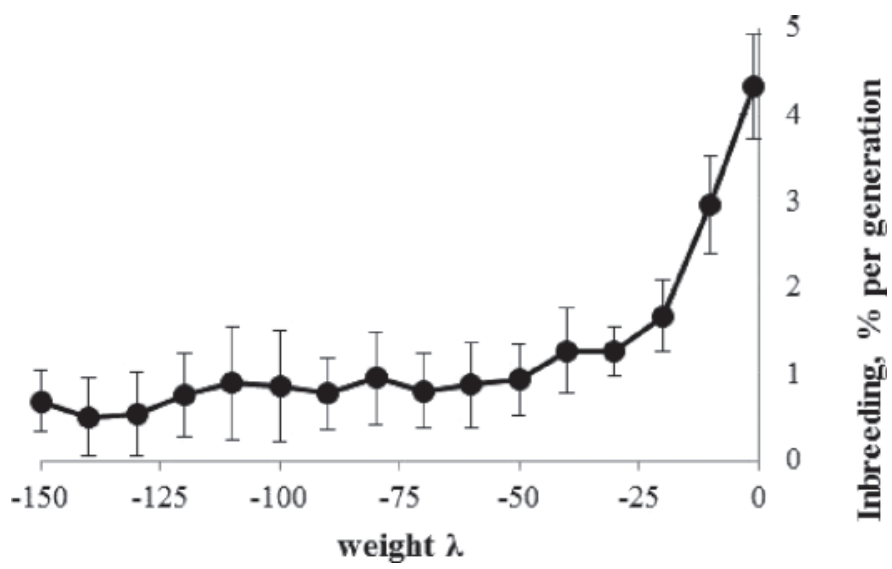

Figure 1. Effect of the weight $\lambda$ on the rate of inbreeding in the scenario OCS30NS.4 (optimum contribution selection scenario with a structure of 30 herds using natural service and $h^{2}$ of 0.44 ); the error bars are $95 \%$ confidence limits. istence of an AI station and a functional infrastructure for semen delivery was assumed. Regular semen collection in mature boars was performed, resulting in 500 doses of semen per boar and year, which was sufficient to inseminate 50 sows twice per year with triple inseminations, assuming an average rate of return to estrus after insemination. Thus, with AI, a mating ratio of 48 was assumed. With OCS, the maximum number of matings per boar was set to 10 or 12 for NS scenarios, and was set to 48 for AI scenarios. This meant that it was possible to select more boars under OCS than under TS, whereas some of them would be used less intensively. Mating of selected animals was performed randomly.

\section{Genetic Model and Breeding Value Estimation}

The effect of selecting for an MQT with a relatively low $\mathrm{h}^{2}\left(\mathrm{~h}^{2}=0.22\right)$, such as ultimate $\mathrm{pH}$, was compared with the effect of selecting for a trait with a relatively high $\mathrm{h}^{2}\left(\mathrm{~h}^{2}=0.44\right)$, such as intramuscular fat content (Rosenvold and Andersen, 2003; van Wijk et al., 2005). Information on half- and full-sibs of the same generation was not available for gilts and young boar candidates at first service owing to their advanced age at slaughter. Because 2 candidates in a litter had the same information (from slaughtered relatives), withinlitter EBV were identical (litter EBV). The infinitesimal model was used to estimate BLUP EBV, with a 


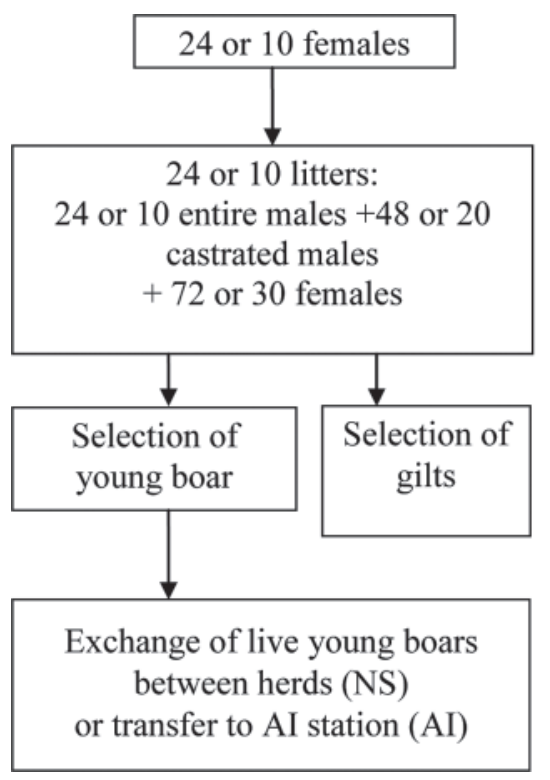

Figure 2. Simulated structure within a herd. NS = natural service.

fixed effect of herd year-season and a random additive genetic effect, together with a random maternal environmental effect and a residual. The additive genetic variance was set to 1 , allowing the estimated genetic change to be expressed in genetic SD.

\section{Computer Simulations}

This study used the stochastic simulation program ADAM (Pedersen et al., 2009) to calculate genetic progress and the rate of inbreeding per generation in each breeding scheme. The ADAM program uses the DMU program package (Madsen and Jensen, 2000) for genetic evaluation. For OCS scenarios, ADAM uses the software EVA (Berg et al., 2009). Both estimated genetic change in MQT and estimated rate of inbreeding in the population were followed over a period of 15 yr (including an initial $4 \mathrm{yr}$ to stabilize the population). All scenarios were replicated 50 times. Statistical tests of differences between scenarios in the evolution of rates of genetic gain and inbreeding were performed using the MIXED procedure (SAS Inst. Inc., Cary, NC), with fixed effects of number of herds $(30,35$, or 77 ; n $=3$ ), type of mating (NS or AI; $\mathrm{n}=2$ ), selection strategy (RS, TS, or OCS; $\mathrm{n}=3$ ), and $\mathrm{h}^{2}$ of selection trait $(0.22$ or $0.44, \mathrm{n}=2)$, and the effect of time $(\mathrm{n}=11$ yr). The repeated measurement option of the MIXED procedure of SAS was used with an autoregressive covariance structure to take into account the correlations between years. The observed accuracy of genetic evaluation and generation interval (GI) came from the same distribution across replicates and across time. Thus, accuracy and GI were analyzed with the ANOVA procedure (GLM procedure). A significance level of $P<$ 0.05 was used when presenting the result. All multiple comparisons of mean values for genetic gain, rate of inbreeding, genetic interval, and accuracy were made using Tukey corrections (SAS Inst. Inc.).

\section{RESULTS}

Genetic gain, rate of inbreeding, GI, and accuracy are shown in Table 2. Number of herds, type of mating, selection rules, $\mathrm{h}^{2}$ of the selection trait, and their interactions all had significant effects on genetic gain, inbreeding, and GI.

\section{Genetic Change}

Figure 3 shows the genetic gain per year with an $\mathrm{h}^{2}$ value of 0.22 , in OCS and TS schemes until yr 15 in populations with 300 female reproducers in 30 herds. The first $4 \mathrm{yr}$ in the simulation show how the perturbations in the system diminished before stabilization from yr 5 and onward. Figure 4a illustrates the differences in cumulative genetic response in populations with 35 herds between the OCS, TS, and RS schemes. The other schemes with different population sizes (30 and 77 herds) followed the same trend. As expected, there was no genetic gain in the RS schemes. Annual genetic gain in the TS schemes was slightly greater than it was in the OCS schemes (on average 0.44 vs. 0.37 genetic SD, $P<0.05$; Table 2). The smaller population size of schemes with 30 and 35 herds resulted in a difference in genetic gain between the TS and OCS schemes (on average +0.08 genetic SD in the TS schemes) that was greater than that observed in the 77-herd schemes (on average +0.03 genetic SD in TS schemes). No differences $(P>0.05)$ were observed in genetic gain between the TS schemes with 35 herds and the TS schemes with 77 herds because male and female selection intensities were unaffected by population size. In the OCS schemes, the genetic gain was, however, greater in the 77-herd schemes than it was in the 35 -herd schemes or in the 30 -herd schemes (on average +0.05 and +0.13 genetic $\mathrm{SD}$, respectively, $P<0.01$ ) because OCS allowed an increased selection intensity in males in a larger population without compromising the increase in relationship of selected animals. The genetic gain in schemes with AI was greater than it was in schemes with NS (on average +0.04 genetic SD, $P<0.05$ ), except for TS schemes with an $\mathrm{h}^{2}$ of 0.22 and OCS schemes with 35 herds and an $h^{2}$ of 0.22 . The $h^{2}$ value significantly affected the genetic gain; a greater $\mathrm{h}^{2}$ gave a greater gain (on average +0.05 genetic SD, $P<0.01$ ).

\section{Rate of Inbreeding}

Figure 4b shows the trend in inbreeding coefficients over time in the OCS, TS, and RS schemes until yr 15, in populations with 35 herds with a value of 0.22 for $h^{2}$. The first inbreeding occurred very quickly in the NS schemes because of the large within-herd recruitment of boars, whereas the first inbreeding occurred later 


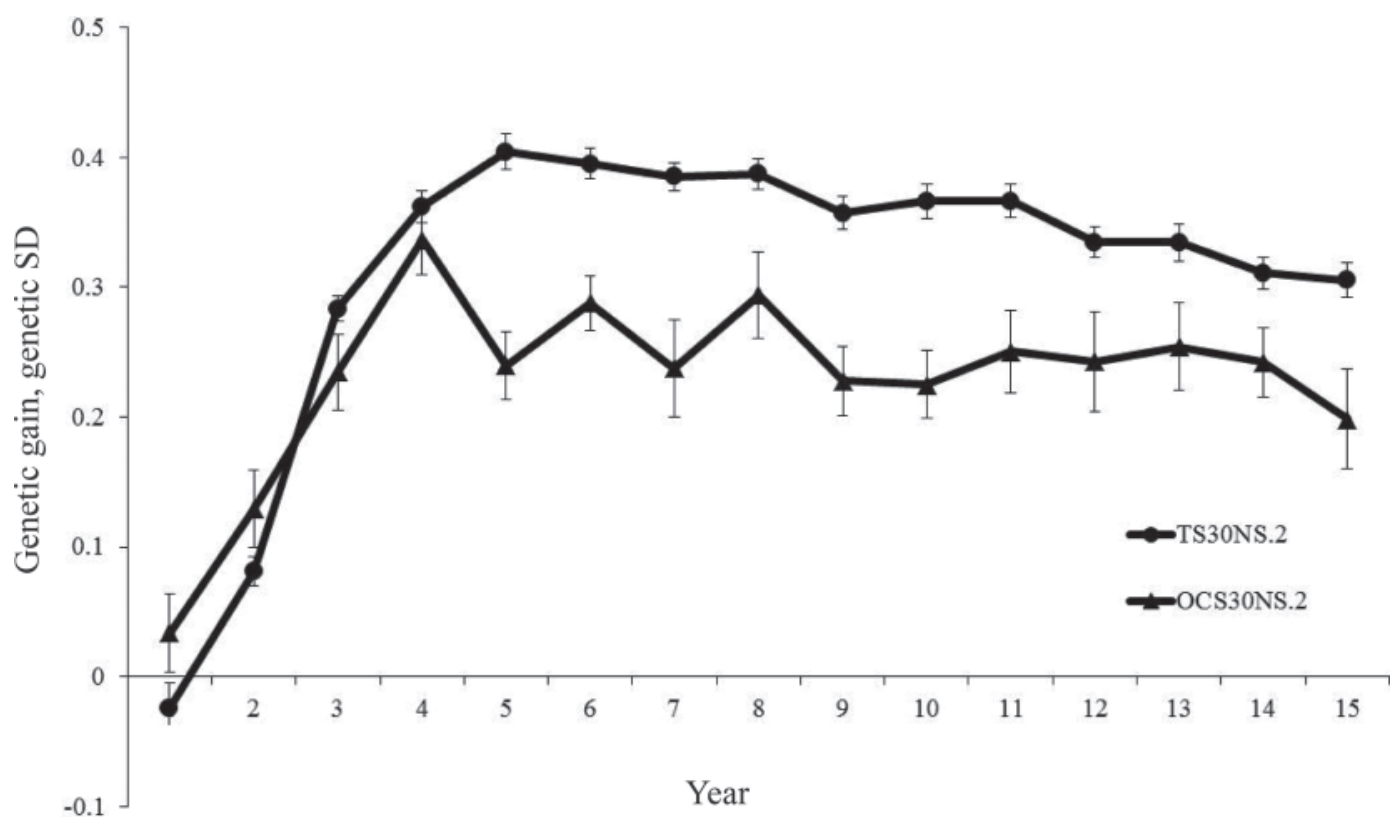

Figure 3. Evolution of the genetic gain per year estimated in BLUP schemes with $h^{2}$ of 0.22 , in a total of 30 herds (TS30NS.2: truncation selection scheme; OCS30NS.2: optimum contribution selection scheme). NS = natural selection.

with AI schemes because of the random mating across herds. This difference was real, but it was an artifact of the starting of the simulation and not a property of the breeding schemes in equilibrium. Inbreeding in the TS schemes (Figure 4b) increased dramatically, and the cumulative inbreeding in the TS scenario exceeded the cumulative inbreeding for OCS from yr 7. The other schemes with different population sizes $(30$ and 77 herds) followed the same trend. The rate of inbreeding per generation was significantly less with

Table 2. Average genetic gain $( \pm \mathrm{SE})$ per year $(\Delta \mathrm{G})$, average rate of inbreeding per generation $(\Delta \mathrm{F})$, generation interval (GI), and average accuracy (r) of simulations from yr 5 to 15

\begin{tabular}{|c|c|c|c|c|c|}
\hline RS30NS & $\mathrm{RS}$ & $0.00 \pm 0.01^{\mathrm{a}}$ & $0.80 \pm 0.30^{\mathrm{a}}$ & $1.75 \pm 0.001^{\mathrm{a}}$ & - \\
\hline OCS30NS.2 & OCS & $0.24 \pm 0.01^{\mathrm{e}}$ & $0.95 \pm 0.60^{\mathrm{a}}$ & $1.69 \pm 0.002^{\mathrm{a}}$ & $0.43 \pm 0.09$ \\
\hline TS30NS.4 & TS & $0.39 \pm 0.01^{\mathrm{d}}$ & $5.50 \pm 0.70^{\mathrm{b}}$ & $1.85 \pm 0.008^{b}$ & $0.41 \pm 0.08$ \\
\hline OCS30NS.4 & OCS & $0.31 \pm 0.03^{\mathrm{b}}$ & $1.20 \pm 0.80^{\mathrm{a}}$ & $1.69 \pm 0.002^{\mathrm{a}}$ & $0.52 \pm 0.09$ \\
\hline OCS35NS.2 & OCS & $0.32 \pm 0.01^{\mathrm{b}}$ & $1.00 \pm 0.31^{\mathrm{a}}$ & $1.52 \pm 0.003^{\mathrm{c}}$ & $0.51 \pm 0.05$ \\
\hline TS35NS.4 & TS & $0.44 \pm 0.02^{\mathrm{e}}$ & $5.10 \pm 0.44^{\mathrm{b}}$ & $1.82 \pm 0.004^{\mathrm{b}}$ & $0.55 \pm 0.04$ \\
\hline OCS35NS.4 & OCS & $0.38 \pm 0.01^{\mathrm{c}}$ & $1.20 \pm 0.36^{\mathrm{a}}$ & $1.51 \pm 0.006^{\mathrm{c}}$ & $0.58 \pm 0.04$ \\
\hline RS35AI & $\mathrm{RS}$ & $0.00 \pm 0.00^{\mathrm{a}}$ & $0.30 \pm 0.02^{\mathrm{a}}$ & $1.74 \pm 0.002^{\mathrm{a}}$ & - \\
\hline TS35AI.2 & TS & $0.42 \pm 0.01^{\mathrm{d}}$ & $4.80 \pm 0.26^{\mathrm{b}}$ & $1.77 \pm 0.004^{\mathrm{a}}$ & $0.44 \pm 0.05$ \\
\hline OCS35AI.2 & OCS & $0.35 \pm 0.02^{b c}$ & $0.97 \pm 0.03^{\mathrm{a}}$ & $1.50 \pm 0.005^{\mathrm{c}}$ & $0.47 \pm 0.04$ \\
\hline TS77NS.4 & TS & $0.45 \pm 0.01^{\mathrm{e}}$ & $2.70 \pm 0.19^{c}$ & $1.82 \pm 0.004^{\mathrm{b}}$ & $0.55 \pm 0.03$ \\
\hline OCS77NS.4 & OCS & $0.41 \pm 0.01^{\mathrm{d}}$ & $1.00 \pm 0.25^{\mathrm{a}}$ & $1.53 \pm 0.005^{\mathrm{c}}$ & $0.58 \pm 0.04$ \\
\hline RS77AI & $\mathrm{RS}$ & $0.01 \pm 0.01^{\mathrm{a}}$ & $0.20 \pm 0.01^{\mathrm{a}}$ & $1.75 \pm 0.002^{\mathrm{a}}$ & - \\
\hline TS77AI.2 & TS & $0.42 \pm 0.02^{\mathrm{d}}$ & $2.88 \pm 0.15^{\mathrm{c}}$ & $1.76 \pm 0.003^{\mathrm{a}}$ & $0.44 \pm 0.04$ \\
\hline OCS77AI.2 & OCS & $0.41 \pm 0.01^{\mathrm{d}}$ & $0.76 \pm 0.02^{\mathrm{a}}$ & $1.49 \pm 0.005^{\mathrm{c}}$ & $0.48 \pm 0.03$ \\
\hline TS77AI.4 & $\mathrm{TS}$ & $0.50 \pm 0.02^{\mathrm{f}}$ & $2.30 \pm 0.10^{\mathrm{c}}$ & $1.76 \pm 0.003^{\mathrm{a}}$ & $0.52 \pm 0.04$ \\
\hline OCS77AI.4 & OCS & $0.47 \pm 0.02^{\mathrm{f}}$ & $0.73 \pm 0.03^{\mathrm{a}}$ & $1.49 \pm 0.004^{\mathrm{c}}$ & $0.55 \pm 0.04$ \\
\hline
\end{tabular}

${ }^{\mathrm{a}-\mathrm{f}}$ Values with different superscripts within the same column are significantly different $(P<0.05)$. Accuracy values did not differ between scenarios.

${ }^{1} \mathrm{RS}=$ random selection; TS $=$ truncation selection based on BLUP breeding values; OCS = optimum contribution selection. 
a

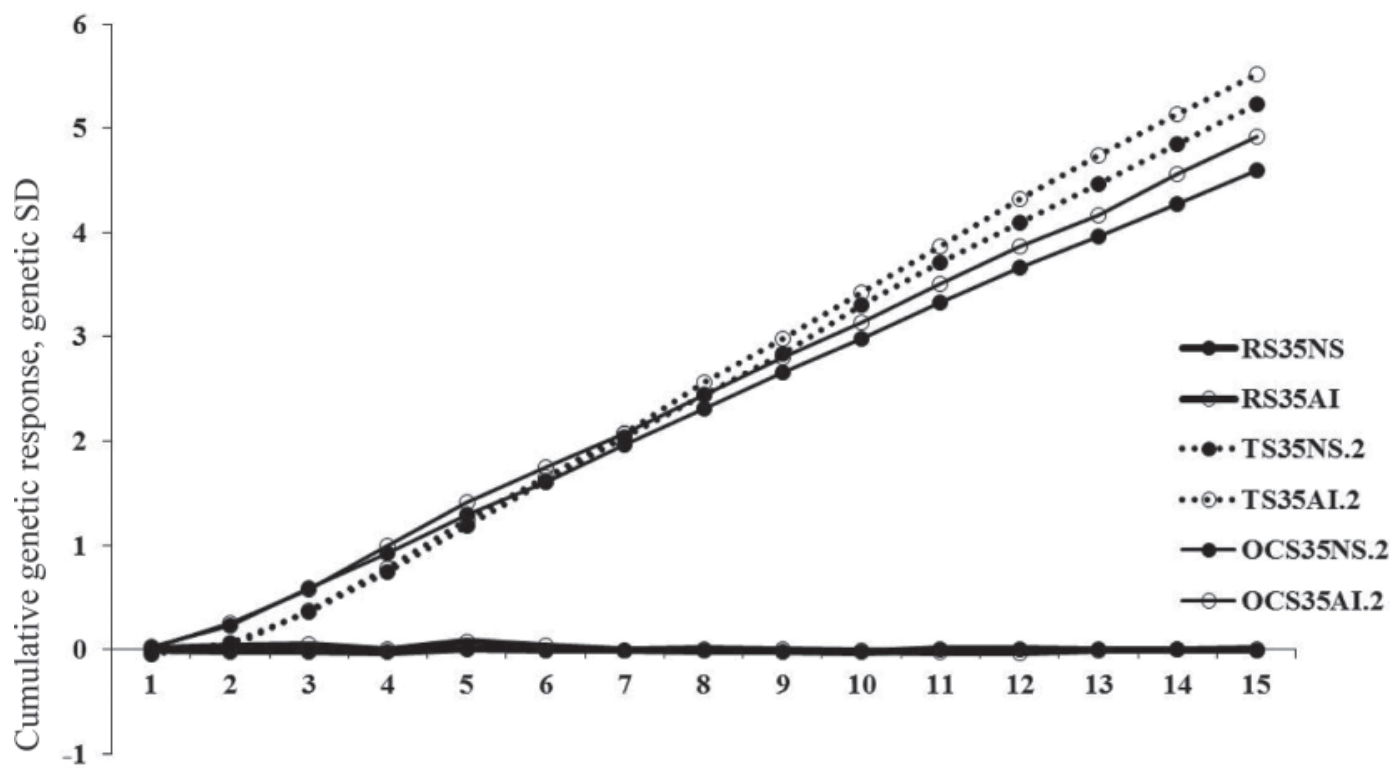

Year

b

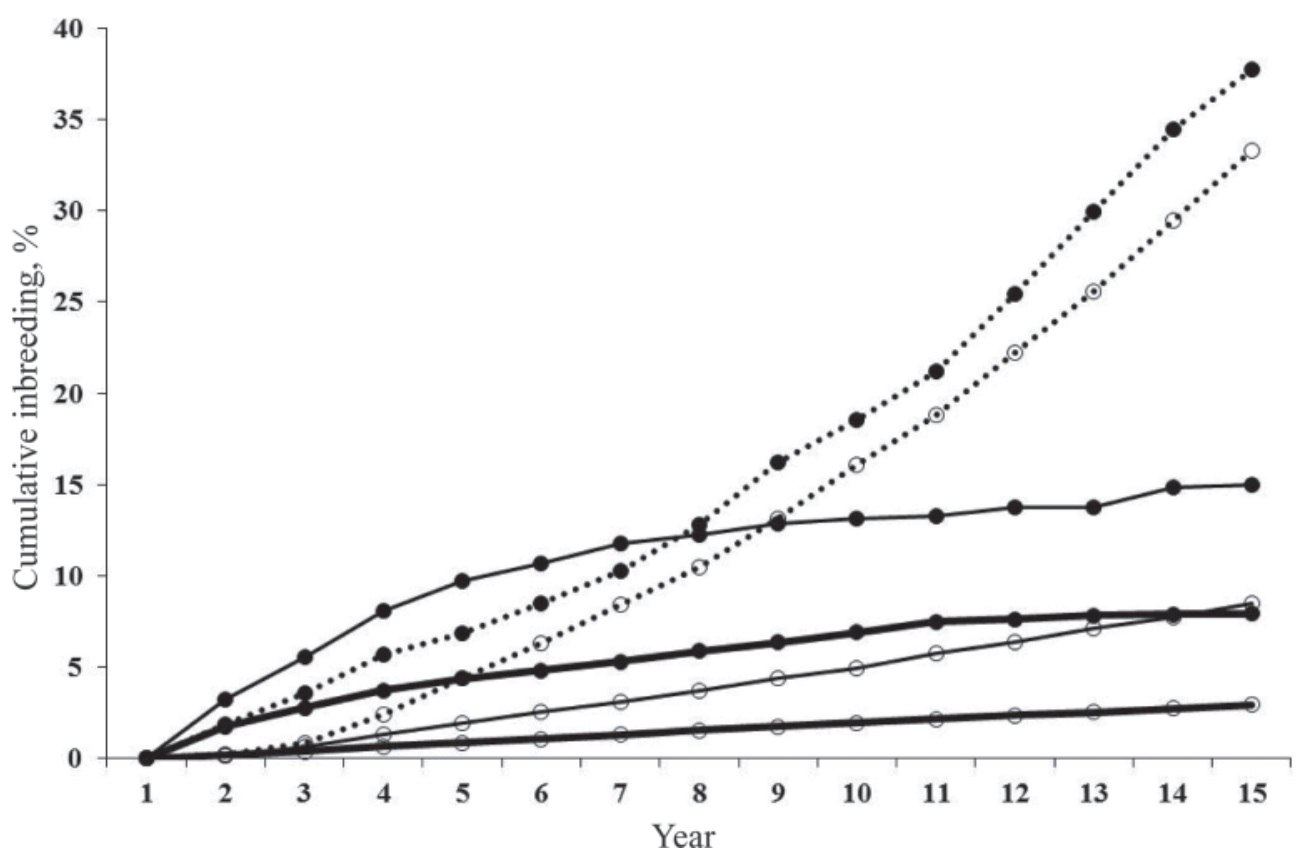

Figure 4. Cumulative genetic response (a) and inbreeding (b) estimated in optimum contribution selection (OCS), truncation selection based on BLUP breeding values (TS), and random selection (RS) schemes in a total of 35 herds with $\mathrm{h}^{2}=0.22$. NS $=$ natural selection.

RS $(0.50 \%)$ and OCS (0.97\%) than with TS $(4.20 \%$; $P<0.01)$. The rate of inbreeding in the TS schemes was significantly affected by population size $(P<0.01)$, with values in the population of 77 herds (on average $2.60 \%$ ) that were less than those in the population of 35 herds (on average $4.60 \%$ ). With an $\mathrm{h}^{2}$ of 0.44 , the rate of inbreeding was less in TS schemes than it was with an $h^{2}$ of 0.22 . The opposite was the case in the OCS schemes. With RS, the rate of inbreeding was less with
AI than with NS, despite fewer boars being selected with AI. This occurred because of the substructuring caused by the limited gene flow between herds with NS. As a result, the rate of inbreeding in RS with NS was also greater $(\Delta \mathrm{F}=0.67 \%)$ than values predicted by the formula derived by Wright $\left[1969 ; \Delta \mathrm{F}=(8 \mathrm{M})^{-1}\right.$ $+(8 \mathrm{~F})^{-1}$, where $\mathrm{M}$ and $\mathrm{F}$ are the numbers of male and female parents; $\Delta \mathrm{F}=0.14 \%]$. As pointed out by Woolliams and Toro (2007), this formula frequently un- 
derestimates the achieved rate of inbreeding because it describes situations in which RS and mating occur among 2 sexes with unrestricted family sizes.

\section{GI and Accuracy}

The GI, ranging from 1.57 (OCS) to $1.83 \mathrm{yr}$ (TS), differed significantly between TS schemes with NS (GI $=1.80 \mathrm{yr})$, OCS schemes $(\mathrm{GI}=1.50 \mathrm{yr})$, and the other scenarios (RS schemes and TS schemes with AI; GI = $1.75 \mathrm{yr}$ ). The average accuracy was 0.46 . It tended to be greater in the OCS schemes than in the TS schemes, but this difference was not significant (Table 2).

\section{DISCUSSION}

The main objective of this study was to show that it is possible to select for a goal trait in a small population of a local breed. The results showed that this was indeed the case. Using BLUP technology to predict the genetic merit of live animals was crucial in our case because the trait was recorded only on slaughtered animals. However, the use of BLUP values for TS resulted in very high rates of inbreeding because of the small population size and the high correlations between the breeding values of relatives. The use of BLUP values for OCS allowed a substantial genetic response, whereas the rate of inbreeding was only marginally greater than it was under RS.

Meat quality was chosen in our simulation because food quality is an important trait for marketing a highquality product and because marketing is an important component of any sustainable breeding program (Woolliams, 2007). Pork from alternative, extensive production systems will always be more expensive than ordinary pork from an intensive system. Although consumers are willing to pay more for pork with enhanced "ethical quality" (Liljenstolpe, 2008), we assumed that the product quality must be at least as good as ordinary pork to justify a higher price. It could be argued that, in general, meat quality is no problem in pigs from local breeds reared extensively and slaughtered at an older age. Even so, the results generated by the application of OCS in this study are of general interest. Optimum contribution selection permits selection for a trait related to the weakest link of the production chain even in a small population. The trait could also be litter size or resistance to a specific disease. Such selection could make an alternative production system based on a local breed more economical and thus improve the sustainability of pig production. Optimum contribution selection could also be used with considerable weight being placed on the relationship of selected parents in populations in which the focus is on conservation and genetic progress is less important.

Genetic gain in the OCS and TS schemes differed significantly. On average, the genetic gain in the OCS schemes amounted to between $69 \%$ (smallest popula- tion, OCS30NS.2 and TS30NS.2) and 98\% (largest population, OCS77AI.4 and TS77AI.4) of the gain in TS schemes. It should be noted that $\lambda$ was the same for all OCS schemes. The rate of inbreeding should be below $1 \%$ in any breeding program claiming to be sustainable (FAO, 2007). If the aim is to keep the rate of inbreeding $\leq 1 \%, \lambda$ could be smaller (i.e., less weight could be placed on the average relationship relative to breeding value) in the larger population selected for the trait with an $h^{2}$ of 0.44 . With a smaller $\lambda$, the difference in genetic gain between TS and OCS would be even smaller.

In our simulation, the population size was chosen to mimic a local breed production system. For instance, the population size used to simulate pig production from 35 herds (24 sows per herd) was comparable with Basque black pied production in France, which includes 29 herds of 18 sows on average (Mercat et al., 2007). The simulated population of 77 herds was comparable with, for example, Black Mallorcan pig production, which includes 79 herds of 20 sows (Jaume et al., 2008). Today, no genetic evaluation is performed on the Basque black pig (J.-Y. Dourmad, French National Institute for Agricultural Research, UMR1079 Systèmes d'Elevage, Nutrition Animale et Humaine, Rennes, France, personal communication about Basque pigs). The Black Mallorcan pig is selected for growth rate, but the selection pressure is quite low (J. Gonzalez, IRTA Food Technology, Carcass and Meat Quality, Finca Camps i Armet, Monells, Spain, personal communication about Mallorcan pigs). The current study shows that, with OCS, it is possible to use genetic evaluation and selection while achieving limited rates of inbreeding even in a small population such as OCS30NS, which included only 300 female reproducers.

The implementation of a genetic evaluation in an OCS scheme requires investments in infrastructure to facilitate the recording of traits, the tracking of the identities of tested animals, and genetic analyses. In addition to producing high-quality products, local breeds have other economic value, such as being insurance for the future development of livestock production and having environmental and cultural functions (Mendelsohn, 2003). The entire economic value of local breeds could be an important argument to convince policy decision makers to design economic incentives to perform selection schemes of local breeds.

With an AI station, the demands on the infrastructure are even greater. In practice, farmers of local breeds seldom use AI (Bonneau et al., 2011). As reviewed by Bidanel et al. (2003), although AI results in greater accuracy of EBV and more rapid access to improved genotypes, it also carries a greater risk of inbreeding. In our simulations, no difference was found in the accuracy of schemes using AI and schemes using NS. The generation interval was longer, and the amount of genetic gain was less in TS schemes with NS than in TS schemes with AI, where $\mathrm{h}^{2}$ was 0.44 . The longer GI is a 
function of the smaller rate of gain, causing older males to be competitive for a longer period (Falconer and Mackay, 1996). With reduced $\mathrm{h}^{2}$, there was, however, no difference in genetic gain between TS schemes with NS and with AI. It is likely that the larger selection intensity in the AI schemes is counteracted by decreased accuracy of selection because of a stronger Bulmer effect. Managing an AI station and distributing semen are expensive. It is possible that within the economic constraints of an alternative production system based on a small population of a local breed, it is more valuable to invest in marketing than in AI.

Even if $\mathrm{RS}$ is performed, the rate of inbreeding increases by $0.8 \%$ in the smallest population. It should be noted, however, that the generation length in the present study was less than 2 yr. Longer GI could be used in a small population in which the conservation of genetic variation over defined time periods is the main focus. It should also be remembered that mating was performed at random, whereas in real populations, there are often rules about maximum coancestry between mates or about the maximum number of offspring per parent. The only rule applied in this simulation was that only 1 boar could be selected from each litter. The advantage of minimum coancestry mating over random mating, in terms of inbreeding rates, is approximately similar with TS and OCS (Sonesson and Meuwissen, 2000). This suggests that the advantage of OCS found in this study should be present even if sophisticated mating rules are applied. Henryon et al. (2009) showed in a simulation study that minimizing the covariance between ancestral contributions (MCAC mating) generated less inbreeding and at least as much genetic gain as minimum coancestry mating. As long as a central organization manages the database and performs the genetic evaluation and OCS, OCS based on BLUP evaluations and MCAC mating should also be feasible in a small population without AI. However, when OCS is used, the pedigree data must be correct and complete, as shown by $\mathrm{S} \varnothing$ rensen et al. (2008) and Oliehoek and Bijma (2009).

In conclusion, an MQT was chosen as the selection trait in this simulation, but the results are relevant for any trait of importance for the marketing of high-quality products from a local breed. Optimum contribution selection can generate considerable genetic progress at a rate of inbreeding similar to that obtained by RS. Confirmation that OCS allows substantial genetic progress while keeping rates of inbreeding at an acceptable level, even in small populations, is both welcome and important in the context of sustainable management and the use of animal genetic resources.

\section{LITERATURE CITED}

Berg, P., M. K. Sørensen, and J. Nielsen. 2009. EVA Interface User Manual. Accessed Nov. 26, 2010. http://eva.agrsci.dk/.

Bidanel, J. P., J. Ricquet, P. Chardon, F. Hatey, P. Le Roy, and D. Milan. 2003. Apport des nouvelles biotechnologies aux pro- grammes d'amélioration génétique du porc. J. Rech. Porcine Fr. 35:355-368.

Bonneau, M., E. Antoine-Ilari, C. Phatsara, D. Brinkmann, M. Hviid, M. G. Christiansen, E. Fàbrega, P. Rodríguez, L. Rydhmer, I. Enting, K. de Greef, H. Edge, J. Y. Dourmad, and S. Edwards. 2011. Diversity of pig production systems at farm level in Europe. J. Chain Network Sci. 11:115-135.

CBD (Convention on Biological Diversity). 2004. In: Seventh Meeting of the Conference of the Parties to the Convention on Biological Diversity (COP 7), Decision VII/32, The Programme of Work of the Convention and the Millennium Development Goals. Mar. 13, 2006. http://www.biodiv.org/decisions/default. aspx $? \mathrm{~m}=\mathrm{COP}-07 \& \mathrm{id}=7769 \& \mathrm{lg}=0$.

Falconer, D. S., and T. F. C. Mackay. 1996. Introduction to Quantitative Genetics. 4th ed. Longman Harlow, New York, NY.

FAO. 2007. The global strategy for the management of farm animal genetic resources and the Interlaken declaration. Accessed Sep. 29, 2011. ftp://ftp.fao.org/docrep/fao/010/a1404e/a1404e00. pdf.

Fimland, E. 2007. Genetic diversity and sustainable management of animal genetic resources, globally. Anim. Gen. Res. Inf. $41: 45-52$.

Gandini, G., and K. Oldenbroek. 2007. Strategies for moving from conservation to utilisation. Pages $29-54$ in Utilisation and Conservation of Farm Animal Genetic Resources. K. Oldenbroek, ed. Wageningen Academic Publishers, Wageningen, the Netherlands.

Grundy, B., B. Villanueva, and J. A. Woolliams. 2000. Dynamic selection for maximizing response with constrained inbreeding in schemes with overlapping generations. Anim. Sci. 70:373-382.

Henryon, M., A. C. Sørensen, and P. Berg. 2009. Mating animals by minimising the covariance between ancestral contributions generates less inbreeding without compromising genetic gain in breeding schemes with truncation selection. Animal 3:13391346.

Jaume, J., M. Gispert, M. A. Oliver, E. Fàbrega, N. Trilla, and J. Tibau. 2008. The Mallorca Black pig: Production system, conservation and breeding strategies. Options Méditerr. A $78: 257-262$.

Liljenstolpe, C. 2008. Evaluating animal welfare with choice experiments: An application to Swedish pig production. Agribusiness 24:67-84.

Madsen, P., and J. Jensen. 2000. A User's Guide to DMU. A Package for Analysing Multivariate Mixed Models. Version 6, release 4. University of Aarhus, Tjele, Denmark.

Mendelsohn, R. 2003. The challenge of conserving indigenous domesticated animals. Ecol. Econ. 45:501-510.

Mercat, M. J. 2007. Analysis of genetic variability of the Basque and Gasconne breeds using genealogical information. Options Mediterr. A 76:51-55.

Meuwissen, T. H. E. 1997. Maximizing the response of selection with predefined rate of inbreeding. J. Anim. Sci. 75:934-940.

Oliehoek, P. A., and P. Bijma. 2009. Effects of pedigree errors on the efficiency of conservation decisions. Genet. Sel. Evol. 41:9.

Ollivier, L., L. Alderson, G. Gandini, J. L. Foulley, C. S. Haley, R. Joosten, A. P. Rattink, B. Harlizius, M. A. M. Groenen, Y. Amigues, M. Y. Boscher, G. Russell, A. Law, R. Davoli, V. Russo, D. Matassino, C. Désautés, E. Fimland, M. Bagga, J. V. Delgado, J. L. Vega-Pla, A. M. Martinez, A. M. Ramos, P. Glodek, J. N. Meyer, G. S. Plastow, K. W. Siggens, A. L. Archibald, D. Milan, M. San Cristobal, G. Laval, K. Hammond, R. Cardellino, and C. Chevalet. 2005. An assessment of European pig diversity using molecular markers: Partitioning of diversity among breeds. Conserv. Genet. 6:729-741.

Pedersen, L. D., A. C. Sørensen, M. Henryon, S. Ansari-Mahyari, and P. Berg. 2009. ADAM: A computer program to simulate selective breeding schemes for animals. Livest. Sci. 121:343-344.

Rosenvold, K., and H. J. Andersen. 2003. Factors of significance for pork quality-A review. Meat Sci. 64:219-237. 
Sonesson, A. K., and T. H. E. Meuwissen. 2000. Mating schemes for optimum contribution selection with constrained rates of inbreeding. Genet. Sel. Evol. 32:231-248.

Sørensen, M. K., A. C. Sørensen, R. Baumung, S. Borchersen, and P. Berg. 2008. Optimal genetic contribution selection in Danish Holstein depends on pedigree quality. Livest. Sci. 118:212-222.

van Wijk, H. J., D. J. G. Arts, J. O. Matthews, M. Webster, B. J. Ducro, and E. F. Knol. 2005. Genetic parameters for carcass composition and pork quality estimated in a commercial production chain. J. Anim. Sci. 83:324-333.

Woolliams, J. 2007. Genetic contributions and inbreeding. Pages 147-166 in Utilisation and Conservation of Farm Animal Ge- netic Resources. K. Oldenbroek, ed. Wageningen Academic Publishers, Wageningen, the Netherlands.

Woolliams, J., and M. Toro. 2007. What is genetic diversity? Pages 55-74 in Utilisation and Conservation of Farm Animal Genetic Resources. K. Oldenbroek, ed. Wageningen Academic Publishers, Wageningen, the Netherlands.

Wray, N. R., and M. E. Goddard. 1994. Increasing long-term response to selection. Genet. Sel. Evol. 26:431-451.

Wright, S. 1969. Effective size of population. Pages 210-220 in Evolution and the Genetics of Populations. Vol. 2: Theory of Gene Frequencies. The University of Chicago Press, Chicago, IL. 
References

This article cites 18 articles, 2 of which you can access for free at: http://www.journalofanimalscience.org/content/90/1/76\#BIBL 